American University Working Paper Series

\title{
Long-term shifts in demand and distribution in neo-Kaleckian and neo-Goodwinian models
}

\author{
Robert A. Blecker*
}

November 2017 [revised, June 2018]

Draft chapter for Hassan Bougrine and Louis-Philippe Rochon (eds), Money and Crises in PostKeynesian Economics: Essays in Honour of Marc Lavoie and Mario Seccareccia (Edward Elgar, forthcoming). [6026 words total]

*Professor of Economics, American University, Washington, DC, USA, blecker@american.edu. The author would like to thank participants at conferences and seminars in New York (Eastern Economic Association), Brasilia (Brazilian Keynesian Association), and Buenos Aires (Universidad Nacional de San Martín) for comments on earlier versions of material in this chapter. 


\section{INTRODUCTION}

The neo-Kaleckian branch of post-Keynesian economics emphasizes the multi-faceted relationships between the functional distribution of income and various indicators of macroeconomic performance, such as the rates of capital accumulation, capacity utilization, and economic growth (Hein 2014; Lavoie 2014). Empirical studies in this tradition have, however, reached diametrically opposed conclusions about whether aggregate demand is normally wageled or profit-led in the short run. As surveyed by Blecker (2016) and Stockhammer (2017), ${ }^{1}$ studies using a "structural" (multi-equation) approach have (with some exceptions) tended to find that most countries have wage-led demand, except for very small or highly open economies, while studies using an "aggregative" approach have typically found that demand is profit-led (often for the same countries or similar panels of countries). The latter studies have frequently relied upon the so-called "Goodwin cycle" variant of the neo-Kaleckian model pioneered by Barbosa-Filho and Taylor (2006), in which it is also found that there is a "profit squeeze" (that is, higher utilization leads to an increased wage share or reduced profit share). ${ }^{2}$ Following Stockhammer (2017), this variant will be referred to as the "neo-Goodwinian" approach.

In spite of these varied empirical findings, one thing is clear: over the past few decades, most advanced capitalist countries (and some emerging market nations as well) have suffered from slower growth along with rising inequality. In particular, wage shares - which in the past usually exhibited the "stylized fact" of mostly cyclical fluctuations around roughly constant trends - have fallen notably in many countries since roughly the 1980s or 1990s, depending on the country (Storm and Naastepad 2012; Karabarbounis and Neiman 2014; Kiefer and Rada 2015; Wolff 2015; Stockhammer and Wildauer 2016). The wage-led demand view suggests a 
ready-made explanation for this coincidence of increasing inequality and worsening performance: various structural changes and policy shifts (globalization, financialization, deregulation, deunionization, and neo-liberal policies generally) have combined to weaken labor relative to capital; the resulting redistribution of income toward profits inevitably causes aggregate demand to be depressed and growth to falter in economies where demand is wage-led. It is less apparent how the coincidence of greater inequality and slower growth in the longer term can be explained by a model in which demand is profit-led. As two skeptics of the profit-led view have written,

despite the fact that in almost all OECD countries real wage growth was significantly restrained after 1980, allowing profitability to recover to its goldenage level, post-1980 macroeconomic performance is in general characterized by lower output growth, lower rates of investment, and higher rates of unemployment than witnessed during the period from 1960 to $1980 \ldots$. The disappointing performance raises the question of why the redistribution of income from wages to profits in a supposedly profit-led demand regime has so far failed to bring about a more adequate long-run economic performance. (Storm and Naastepad 2012, p. 113)

This chapter will argue that there is a logically coherent explanation for the paradox that an increased profit share has failed to bring about improved macro performance at medium-term horizons (across a few decades) in economies that have profit-led demand in the short run (that is, at business-cycle frequencies). The key to this explanation lies in the other finding of the neoGoodwinian literature: that the distributive relationship slopes upward in utilization-wage share space, or in other words, the economy exhibits a "profit-squeeze" in distribution. If the distributive relationship slopes upward while the aggregate demand relationship slopes downward, then any medium-run shifts in a southwesterly direction (toward lower utilization/growth rates and a lower wage share) should be driven primarily by downward shifts in the aggregate demand relationship. Thus, any factors that tend to depress aggregate demand will also move the economy toward lower points on the distributive relationship - lower 
combinations of the wage share and utilization rate (or some other measure of output or demand) - provided that this relationship is characterized by profit-squeeze behavior.

Essentially, chronically depressed aggregate demand relieves the profit-squeeze on capital by holding down output and employment, thereby preventing workers from reaping wage gains both during cyclical upturns and over longer periods. Thus, this explanation reverses the causality in the standard long-run story: in this alternative view, it is chronically depressed aggregate demand that prevents workers from winning wage gains in line with their productivity growth, rather than the falling wage share being an exogenous cause of depressed demand.

Before proceeding further, several qualifications are in order. First, many economists have rejected the entire idea of characterizing economic systems as uniquely either wage-led or profit-led (for example, Nikiforos and Foley 2012; Dos Santos 2015; Palley 2017; Skott 2017). I am sympathetic with that critique, especially since my own previous work has emphasized that the impact of a redistribution of income between wages and profits on aggregate demand varies according to the source of the shift in distribution in an open economy (Blecker 1989, 2011). In this chapter, I apply the wage-led versus profit-led distinction only to the slope of the aggregate demand relationship in the short run; I do not use it to characterize the behavior of the overall economic system or longer-term outcomes.

Second, some economists have argued that the findings of profit-led demand are likely to be biased by factors that are not controlled for in the neo-Goodwinian empirical studies. Lavoie (2014, 2017) argues that those findings could be driven by the procyclical behavior of labor productivity in the presence of overhead labor. Assuming that firms do not layoff overhead labor in proportion to the decline in output during a cyclical downturn, labor productivity will fall in a recession and rise in the recovery, and since the wage share equals the ratio of the real wage to 
labor productivity, the wage share will naturally move in the opposite direction. This endogenous movement of the wage share could create a misleading impression that demand is profit-led, since the profit share would be falling as utilization falls and conversely. Also, Stockhammer and Michell (2017) demonstrate theoretically that a debt-driven "Minsky cycle" can mimic a profitdriven Goodwin cycle even when aggregate demand is not truly profit-led. ${ }^{3}$

Third, and most importantly, the argument in this chapter is intended only to establish a logical possibility, not to claim that it is the only or exclusive explanation for the coincidence of worsened economic performance and higher profit shares. It is clear that the massive structural changes brought about by the globalization of production and finance and shifts toward neoliberal policies have directly weakened labor's bargaining position and inhibited workers from winning wage increases commensurate with their rising productivity, and the resulting fall in wage shares (especially for production workers) certainly could contribute to depressed economic activity in the long term. Indeed, I have argued elsewhere that the impact of distribution on demand and growth is likely to vary over different time horizons (Blecker 2016): the positive effects of profitability on investment and negative effects of unit labor costs on net exports are likely to dominate in the short run, implying profit-led demand at business-cycle frequencies, whereas the positive effects of high wages on consumption are likely to dominate in the longer term, implying wage-led demand over longer time horizons. ${ }^{4}$ But what this chapter emphasizes is not the demand relationship per se, but rather how it interacts with the distributional relationship in such a way that depressed demand and growth could be as much causes of a more unequal distribution of income as they are consequences of the latter. 


\section{THEORETICAL FRAMEWORK}

Following Barbosa-Filho and Taylor (2006) and Kiefer and Rada (2015), among others, a generalized neo-Kaleckian model of capacity utilization and income distribution can be written as

$$
\begin{aligned}
& \dot{u}=f(u, \psi) \\
& \dot{\psi}=g(u, \psi)
\end{aligned}
$$

where $u$ is the capacity utilization rate, $\psi$ is the wage share, $f$ and $g$ are functions, and a dot over a variable indicates a time derivative. It should be noted that nothing in the following discussion hinges on using the utilization rate as the indicator of aggregate output or economic activity; similar models could be specified using alternative measures such as the growth rate of GDP or rate of capital accumulation instead.

The partial derivatives of functions (1) and (2) can take various signs, thus leading to many different configurations of the two nullclines $(\dot{u}=0$ and $\dot{\psi}=0)$ and different types of dynamics both stable and unstable. Two stable cases that have (if the reader will pardon the pun) attracted much attention in the literature are the ones depicted in Figure 1. For convenience, the utilization nullcline ( $\dot{u}=0)$ will be referred to as the aggregate demand curve (AD), while the distribution nullcline ( $\dot{\psi}=0$ ) will be called the distributive curve (DC). Panel (a) in Figure 1 illustrates the typical findings in most of the wage-led literature: AD slopes upward in $u \times \psi$ space, while DC slopes downward - the latter reflecting the negative effect of GDP growth on the wage share found by Stockhammer (2013). ${ }^{5}$ Following Kiefer and Rada (2015), we will call the downward-sloping DC curve the case of a "wage squeeze." As will be seen below, in the wage-led demand case the slope of DC is of less importance, provided that it is not positive and 
steeper than $\mathrm{AD}$ (in which case the equilibrium would become unstable); ${ }^{6}$ rather it is the direction of shifts in DC that matters the most. In contrast, panel (b) in Figure 1 shows the neoGoodwinian case, in which AD is downward-sloping (reflecting profit-led demand) while DC is upward-sloping (exhibiting a profit squeeze). In the latter case, the slope of DC is quite important, for reasons that will soon become clear. In both cases shown in Figure 1, the equilibrium is a stable focus (spiral), but in panel (a) the rotation of the adjustment path is clockwise while in panel (b) it is counter-clockwise. ${ }^{7}$

[Insert Figure 1 about here]

The graphs in Figure 1 depict short-run cycles around short-run equilibrium points. But as the raw data show - and the econometric estimates of Kiefer and Rada (2015) confirm - the equilibria in these figures have drifted in a southwesterly direction, that is, toward lower equilibrium levels of both utilization rates (measured by output gaps) and the wage share, in most of the advanced economies over the past few decades. What could account for such a medium-term shift in the AD-DC equilibrium? The two alternative visions depicted in Figure 1 suggest different explanations of what accounts for these longer-term changes.

Starting with the wage-led view, the explanation is relatively straightforward and indeed is implicit in a large number of studies (for example, Lavoie and Stockhammer 2013). In this view, various structural changes and policy shifts have combined to weaken labor and redistribute income toward capital. These underlying forces include globalization, financialization, deunionization, and other transformations generally associated with the "neoliberal" policy paradigm (Stockhammer 2013). As a result, the DC curve must have shifted downward sometime (depending on the country) between the 1980s and early 2000s. With the AD curve sloping upward, a downward shift of the DC curve would naturally have led to 
reductions in the equilibrium levels of both the wage share and the utilization (or growth) rate, as shown by the shift of DC to DC' in panel (a) of Figure 2. Note that the negative slope of DC is not crucial to this argument; if DC were either horizontal (flat) or positively sloped but flatter than $\mathrm{AD}$, a downward shift in DC would still cause the same qualitative outcome in terms of depressing equilibrium $u^{*}$ and $\psi^{*} .^{8}$

[Insert Figure 2 about here]

Of course, in this view, there could also have been shifts in the AD curve, for example as a result of contractionary macro policies such as fiscal austerity, but the primary explanation for a long-term, simultaneous decline in both $u^{*}$ and $\psi^{*}$ would have to reside in a larger downward shift in DC. Also, this view allows for temporary booms in aggregate demand facilitated by asset-price bubbles and debt-driven spending in some countries, or export-led "mercantilist" expansions in others (Hein and Mundt 2013). However, these types of expansionary forces are inherently self-limiting because they lead to unsustainable financial positions, and hence do not persist in the long run.

Alternatively, the neo-Goodwinian case depicted in panel (b) of Figure 1 suggests a different causal mechanism through which many of the same underlying structural transformations and policy changes could have led to the appearance of the medium-run shifts. In this case, it must instead have been a downward shift in the AD curve, sliding along an upward-sloping DC curve that would account for the observed medium-term downward drift in the equilibrium levels $u^{*}$ and $\psi^{*}$, as shown by the shift of $\mathrm{AD}$ to $\mathrm{AD}^{\prime}$ in panel (b) of Figure 2 . Again, it could be allowed that the downward drift of AD might be offset temporarily by various sorts of unsustainable expansionary forces (asset bubbles, debt-led consumption, or export-led booms), and (relatively smaller) shifts in DC could also be accommodated in the story, but the 
primary driver of the medium-term trends would have to be a persistent downward shift in AD over the long term.

The cases depicted in the two panels of Figure 2 represent only two extreme possibilities, in which only one curve (AD or DC) shifts in the medium run; hence, either of these scenarios seems quite unlikely. If both curves shift, however, each view requires that the two curves move in a precise fashion, and in some cases the shift in one curve must dominate the shift in the other. For example, in the wage-led/wage-squeeze view, long-term declines in $u^{*}$ and $\psi^{*}$ will result only if the leftward shift in $\mathrm{AD}$ is dominated by a larger downward shift in DC (otherwise, $\psi^{*}$ could end up higher instead of lower, because reduced utilization boosts the wage share), as shown in panel (a) of Figure 3. In the neo-Goodwinian (profit-led/profit-squeeze) view, any downward shift in DC must be dominated by a larger downward shift in AD (otherwise, $u^{*}$ could end up higher instead of lower, because a lower wage share stimulates aggregate demand), as seen in Figure 3, panel (b).

[Insert Figure 3 about here]

Yet another possibility is that both AD and DC could slope upward, thus combining wage-led demand with a profit-squeeze in distribution. In the stable case in which both curves are positively sloped and $\mathrm{AD}$ is steeper than $\mathrm{DC},{ }^{9}$ there is no need for the shift in either curve to dominate the other: in this case, any combination of a downward shift in DC and a leftward shift in $\mathrm{AD}$ will yield simultaneous declines in the long-run equilibrium levels of $u^{*}$ and $\psi^{*}$, as shown in panel (c) of Figure 3. 


\section{REEVALUATING THE EMPIRICAL EVIDENCE}

Kiefer and Rada (2015) modified the neo-Goodwinian model of Barbosa-Filho and Taylor (2006) to allow for long-term shifts in the equilibrium values of capacity utilization (measured by the output gap) and the wage share. Using panel data for 13 OECD countries, they found that demand is profit-led and distribution exhibits a profit-squeeze in the short run. However, Kiefer and Rada also found that the equilibrium of their Goodwin cycle system has drifted down and to the left in utilization-wage share space in the longer term. Kiefer and Rada attribute part of this long-term movement to a "race to the bottom" among the included countries, as indicated by a negative effect of the weighted average wage shares of the other countries in the sample on the equilibrium wage share of each included country (they found no significant effect on the equilibrium utilization rate). The authors acknowledge that their methodology cannot identify the causal mechanisms through which this race-to-the-bottom effect operates.

In contrast, Stockhammer and Wildauer (2016) studied the drivers of aggregate demand for a panel of 18 OECD countries using a structural model with separate equations for consumption, investment, exports, and imports. As in previous studies applying a similar methodology to individual countries (for example, Hein and Vogel 2008; Onaran and Galanis 2012), Stockhammer and Wildauer find that most countries - especially the larger and relatively more closed ones - have wage-led demand overall, while some of the smaller and more open countries have profit-led demand. ${ }^{10}$ Nevertheless, in all cases the net effects of income distribution on demand are relatively small, suggesting that the AD curve has only a slightly positive (or in some cases negative) slope. Stockhammer and Wildauer find that the primary drivers of the expansion that preceded the financial crisis of 2008-2009 were not distributional 
shifts, but rather changes in financial variables - especially asset prices (stock market and housing price indexes) and debt accumulation (where household debt had a positive effect on consumption expenditures). Like other authors in this genre, Stockhammer and Wildauer treat the wage share as exogenous.

A number of recent studies have tested for the drivers of falling wage shares. Stockhammer (2013) found that decreasing wage shares in a panel of 71 countries (including both advanced and developing nations) were principally explained by variables representing financialization, globalization, and retrenchment of welfare states. Stockhammer also found that technological change had a small but statistically significant negative effect on the wage share in the advanced economies, and no significant effect in developing countries. Using a neoclassical model, Karabarbounis and Neiman (2014) attributed falling wage shares in a sample of 59 countries to the decreasing relative price of investment goods, which they claim induces strong substitution of capital for labor in production.

According to the estimates of Elsby et al. (2013), falling wage shares in US industries are mainly driven by increasing import penetration and offshoring of labor-intensive activities, especially in manufacturing. De Loecker and Eeckhout (2017) identified a sharp increase in average markup rates (especially with firms weighted by their market shares) as a cause of the falling labor share in the US economy. Autor et al. (2017) found that the falling US labor share is driven by increasing industrial concentration, as the firms that are increasing their market shares also have the highest profit shares so that weighted-average, industry-level profit shares are increasing. ${ }^{11}$ Furceri and Loungani (2018) find that capital account liberalization has a positive effect on inequality (as measured by Gini coefficients) and a negative effect on labor shares, using panel data for 149 countries. ${ }^{12}$ 
However, in many of these studies it is not clear whether what is being estimated is a shift in the distributional relationship (DC) or the change in the equilibrium level of the wage share $\left(\psi^{*}\right)$. For example, in Furceri and Loungani (2018) and Jayadev (2007), we cannot tell whether capital account liberalization affects distribution directly by shifting DC (for example, because increased capital mobility weakens workers' bargaining power or helps to finance corporate takeovers that increase concentration), or rather depresses aggregate demand and shifts AD downward (perhaps because capital account liberalization pressures governments to maintain more contractionary macro policies in order to attract greater capital inflows, or because such inflows lead to currency appreciation), in which case the impact on the wage share would be indirect (and negative, assuming the profit-squeeze case). In general, the micro-based (industryor firm-level) studies (such as Elsby et al., De Loecker and Eeckhout, and Autor et al.) are probably estimating shifts in DC, while the more macro-level studies (such as Kiefer and Rada, Stockhammer, and Furceri and Loungani) are more likely to be finding changes in $\psi^{*}$.

Similar considerations apply to studies that have sought to estimate the causes of depressed aggregate demand. Several studies have found evidence for contractionary demandside effects of financialization. Onaran et al. (2011) found that an increase in the rentiers' income share has a net depressing effect on private domestic demand (the sum of consumption plus investment) in the US economy, regardless of whether this increase is modeled as coming at the expense of workers' wages or firms' retained profits. Orhangazi (2008) found that corporate payouts (the sum of interest expense, cash dividends, and stock buybacks) have a negative and significant effect on investment by US nonfinancial corporations, while financial profits (the sum of interest income and equity in net earnings) have a negative and significant effect in larger firms. Tori and Onaran (2017) found that financial payouts (interest plus dividends) and financial 
income have negative effects on investment in physical capital by nonfinancial corporations in a sample of western European countries. In regard to consumption, Cynamon and Fazzari (2013) and Kim et al. (2015) have analyzed how financialization allows middle-class consumers to increase spending via debt accumulation in spite of stagnant earnings (or to maintain spending when earnings fall) in the short run, but these studies also emphasize that such debt-led household spending is unsustainable in the long run when consumption becomes constrained by increased debt burdens. Given that all these studies have focused on particular components of aggregate demand (consumption and/or investment), they are most likely identifying downward shifts in $\mathrm{AD}$, but these same shifts could also have a positive or negative impact on the equilibrium wage share depending on the slope of DC.

Another potential culprit for explaining a downward shift in $\mathrm{AD}$ is increasing wage inequality, for example, in the form of increasing wage gaps between professional-managerial labor and production workers. Palley (2017) shows theoretically that a redistribution of labor income away from wages of production workers and toward salaries of "capitalist-managers" (professional and managerial labor) can depress aggregate demand, regardless of whether demand is profit- or wage-led. However, empirical studies that have attempted to find effects of increased personal income inequality in depressing consumer demand (or demand generally) have yet to find much evidence for such effects (for example, Stockhammer and Wildauer 2016). In addition to financialization and wage inequality, shifting macroeconomic policy regimes can also help to explain persistent downward pressures on aggregate demand. Since (roughly) the 1980s or 1990s, most advanced economies - and many emerging economies as well - have adopted macro policy regimes that arguably contain inherently contractionary biases. In terms of monetary policy, the shifts toward more independent central banks and more explicit 
inflation targeting are of special importance. In such regimes, central banks respond quickly and forcefully to expected increases in inflation by tightening monetary policy (usually by raising the short-term policy interest rate). ${ }^{13}$ In practice, what this means is that as soon as nominal wages (or unit labor costs) start to increase more rapidly in an expansionary period, central banks immediately clamp down and squelch the growth that threatens to push wages up. The result is that inflation targeting can have chronically depressing effects on output and employment, which in turn dampen wage increases and put downward pressure on the wage share by short-circuiting the profit-squeeze mechanism. In the US, the Federal Reserve often starts raising interest rates during a cyclical expansion even before an actual upturn in wages or inflation occurs, on the theory that falling unemployment will inevitably cause wages to rise "too fast" and inflation to increase.

The stricter are the inflation targeting policies (for example, the lower is the policy objective for inflation and the higher is the estimated "natural rate of unemployment"), the more aggregate demand will be chronically depressed, with negative effects on the wage share if the DC relationship exhibits a profit-squeeze. Of course, the principle that monetary policy has nonneutral effects on output and distribution in the long run is a core tenet of post-Keynesian theory, and one that is frequently cited in critical discussions of contemporary central bank policies (for example, in Lavoie and Seccareccia 2004; Epstein and Yeldan 2009; Lavoie 2014). Indeed, the post-Keynesian literature often emphasizes the distributional impact of monetary policy, but mainly in relation to the distribution of capital income between rentiers and firms (see Rochon and Setterfield 2012). In contrast, the potential for conservative monetary policies to depress wage shares in economies characterized by a "profit-squeeze" in distribution has perhaps not received as much emphasis. 


\section{CONCLUSIONS}

The findings of profit-led demand and neo-Goodwinian cyclical dynamics in some empirical studies have led to widespread skepticism of how such behavior could be compatible with the observed medium-term declines in both macro performance (utilization or growth rates) and wage shares in various countries. But since those findings pertain only to short-run, cyclical behavior, they are not necessarily inconsistent with the observed medium-term trends. This chapter has shown that profit-led demand and neo-Goodwinian cycles can potentially be reconciled with those trends, but only if there is a profit-squeeze in distribution and the shifts in the aggregate demand relationship dominate the shifts in the distributive relationship.

However, it should be emphasized that this is only a logical possibility, and much more theoretical and empirical work is required to tease out the channels through which various kinds of structural forces and policy shifts have affected both income distribution and aggregate demand in the long term. If demand or growth is in fact wage-led - especially over longer periods than typical business cycle frequencies - then it could still be true that distributional shifts against labor help to account for chronic shortfalls of demand (or disappointing growth rates). Also, if Lavoie is correct that cyclical movements in the wage share are largely driven by endogenous fluctuations in labor productivity rather than by the behavior of the real wage, as the empirical results in Cauvel (2018) suggest, then all models that assume that the wage share is an adequate measure of distributional forces would have to be re-thought. Thus, it is important for future research to focus on better understanding what determines the relative shares of wages and profits and analyzing the multidirectional causality between demand, distribution, and other 
factors over both short-run cycles and longer time horizons.

\section{NOTES}

${ }^{1}$ For earlier surveys of the empirical literature, see Onaran and Galanis (2012) and Lavoie and Stockhammer (2013).

${ }^{2}$ See also Kiefer and Rada (2015) and Carvalho and Rezai (2016). All of these models differ from the original model of Goodwin (1967), which was a neo-Marxian model that generated limit cycles in the wage share and employment rate, but did not consider variable capacity utilization. Therefore, we will follow Stockhammer (2017) in referring to the neo-Kaleckian Goodwin cycle models as "neo-Goodwinian."

${ }^{3}$ Cauvel (2018) finds empirical evidence showing that the profit-led demand finding in aggregative models is sensitive to controlling for the endogeneity of labor productivity, but not to the inclusion of controls for debt variables.

${ }^{4}$ Charpe and Bridji (2017) have found evidence consistent with this hypothesis using time-frequency (wavelet) analysis applied to very long-term data for the US, UK, and France. Barrales and von Arnim (2017) failed to find evidence for wage-led demand in the long run using similar methods applied to US data, but using a much shorter sample period that may have missed truly long-run frequencies.

${ }^{5}$ Stockhammer's (2013) finding is not strictly comparable to most of the neo-Goodwinian estimates, however, because he measured output effects by the GDP growth rate rather than the capacity utilization rate. Also, Stockhammer (2017) clarifies that his version of a neo-Kaleckian model does not emphasize cycles; it would probably be better to think of his approach as one in which distribution adjusts much more slowly than output, so that the economy is always on the $\mathrm{AD}$ curve in the short run - or, alternatively, that $\mathrm{DC}$ is horizontal in the short run.

${ }^{6}$ Most empirical studies using the structural approach implicitly assume that $\psi$ is exogenous, in which case DC would be horizontal in the short run. However, Barrales and von Arnim (2017) find evidence of bidirectional Granger-causality between $u$ and $\psi$ using US time-series data.

${ }^{7}$ Barrales and von Arnim (2017) find that US data exhibit counter-clockwise rotations in $u \times \psi$ space at short and medium horizons, using wavelet analysis.

${ }^{8}$ If DC was upward sloping and steeper than $\mathrm{AD}$, the equilibrium would become unstable.

${ }^{9}$ Although this case is stable, it does not generate any cycles; the equilibrium is a stable node rather than a focus or spiral. Logically, there is a fourth possibility of both curves sloping downward, which would entail profit-led demand and a wage-squeeze, but I am not aware of any theoretical or empirical support for this combination.

${ }^{10}$ Given their panel estimation methods, Stockhammer and Wildauer had to assume common coefficients for all countries. However, the estimated coefficients were weighted by the shares of the various components of output (consumption, investment, exports, and imports) in calculating the marginal effects of the wage share for each country, and these effects differ between the countries because of different weights.

${ }^{11}$ Post-Keynesian economists will, of course, find strong echoes in this analysis of the link between increasing industrial concentration and rising average profit margins emphasized by Steindl (1952 [1976]).

${ }^{12}$ The result for labor shares corroborates the earlier findings of Jayadev (2007).

${ }^{13}$ For evidence and discussion related to the output or growth costs of inflation-targeting policy regimes, see Brito and Bystedt (2010), Epstein and Yeldan (2010), and Risler (2016), among others. 


\section{REFERENCES}

Autor, D., D. Dorn, L. Katz, C. Patterson, and J. Van Reenen (2017), "The fall of the labor share and the rise of superstar firms," manuscript, MIT, May.

Barbosa-Filho, N.H. and L. Taylor (2006), "Distributive and demand cycles in the US economy: a structuralist Goodwin model," Metroeconomica, 57(3), 389-411.

Barrales, J. and R. von Arnim (2017), "Longer run distributive cycles: wavelet decompositions for the US, 1948-2011," Review of Keynesian Economics, 5(2), 196-217.

Blecker, R.A. (1989), "International competition, income distribution and economic growth," Cambridge Journal of Economics, 13(3), 395-412.

Blecker, R.A. (2011), "Open economy models of growth and distribution," in E. Hein and E. Stockhammer (eds), A Modern Guide to Keynesian Macroeconomics and Economic Policies. Cheltenham: Edward Elgar, pp. 215-39.

Blecker, R.A. (2016), "Wage-led versus profit-led demand regimes: the long and the short of it," Review of Keynesian Economics, 4(4), 373-90.

Brito, R.D., and B. Bystedt (2010), "Inflation targeting in emerging economies: panel evidence," Journal of Development Economics, 91(2), 198-210.

Carvalho, L. and A. Rezai (2016), "Personal income inequality and aggregate demand," Cambridge Journal of Economic, 40(2), 491-505.

Cauvel, M. (2018), Three Essays on the Empirical Estimation of Wage-Led and Profit-Led Demand Regimes, unpublished PhD dissertation, American University, Washington, DC (in preparation).

Charpe, M. and S. Bridji (2017), "Cycles in labor share and their impact on growth: a timefrequency analysis," manuscript, ILO, January.

Cynamon, B.Z., and S.M. Fazzari (2013), "The end of the consumer age," in B.Z. Cynamon, S.M. Fazzari, and M. Setterfield (eds), After the Great Recession: The Struggle for Economic Recovery and Growth. New York: Cambridge University Press, pp. 129-57.

De Loecker, J. and J. Eeckhout (2017), 'The rise of market power and the macroeconomic implications', National Bureau of Economic Research, Working Paper 23687, August.

Dos Santos, P.L. (2015), 'Not 'wage-led' versus 'profit-led,' but investment-led versus consumption-led growth," Journal of Post Keynesian Economics, 37(4), 661-86.

Elsby, M.W.L., B. Hobijn, and A. Şahin (2013), “The decline of the U.S. labor share,” Brookings Papers on Economic Activity, Fall, 1-52. 
Epstein, G., and E. Yeldan (eds) (2010), Beyond Inflation Targeting: Monetary Policy For Employment Generation and Poverty Reduction. Cheltenham: Edward Elgar.

Furceri, D., and P. Loungani (2018), "The distributional effects of capital account liberalization," Journal of Development Economics, 130 (January), 127-44.

Goodwin, R. M. (1967), “A growth cycle,” in Feinstein, C. (ed.), Socialism, Capitalism and Economic Growth, Cambridge: Cambridge University Press.

Hein, E. (2014), Distribution And Growth After Keynes: A Post-Keynesian Guide, Cheltenham, UK: Edward Elgar.

Hein, E., and M. Mundt (2013), "Financialization, the financial and economic crisis, and the requirements and potentials for economic recovery," in M. Lavoie and E. Stockhammer (eds), Wage-led Growth: An Equitable Strategy for Economic Recovery, Basingstoke: Palgrave Macmillan.

Hein, E., and L. Vogel (2008), "Distribution and growth reconsidered: empirical results for six OECD countries," Cambridge Journal of Economics, 32(3), 479-511.

Jayadev, A. (2007), "Capital account openness and the labour share of income," Cambridge Journal of Economics, 31(3), 423-43.

Karabarbounis, L., and B. Neiman (2014). "The global decline of the labor share," Quarterly Journal of Economics, 129(1): 61-103.

Kiefer, D. and C. Rada (2015), "Profit maximising goes global: the race to the bottom," Cambridge Journal of Economics, 39(5), 1333-50.

Kim, Y.K., M. Setterfield, and Y. Mei (2015), "Aggregate consumption and debt accumulation: an empirical examination of US household behaviour," Cambridge Journal of Economics, $39(1), 2015,93-112$.

Lavoie, M. (2014), Post-Keynesian Economics: New Foundations, Cheltenham: Edward Elgar.

Lavoie, M. (2017), "The origins and evolution of the debate on wage-led and profit-led regimes," European Journal of Economics and Economic Policies: Intervention, 14(2), 200-21.

Lavoie, M., and M. Seccareccia (eds) (2004), Central Banking in the Modern World: Alternative Perspectives, Cheltenham: Edward Elgar.

Lavoie, M., and E. Stockhammer (eds) (2013), Wage-led Growth: An Equitable Strategy for Economic Recovery, Basingstoke: Palgrave Macmillan.

Nikiforos, M., and D. K. Foley (2012), "Distribution and capacity utilization: conceptual issues and empirical evidence," Metroeconomica, 63(1), 200-29. 
Onaran, Ö. and G. Galanis (2012), "Is Aggregate Demand Wage-Led Or Profit-Led? National and Global Effects," Conditions of Work and Employment Series No. 40, International Labour Office, Geneva.

Onaran, Ö., E. Stockhammer and L. Grafl (2011), "The finance-dominated growth regime, distribution, and aggregate demand in the US," Cambridge Journal of Economics, 35(4), 637-61.

Orhangazi, Ö. (2008), "Financialisation and capital accumulation in the non-financial corporate sector: A theoretical and empirical investigation on the US economy: 1973-2003," Cambridge Journal of Economics, 32(6): 863-86.

Palley, T.I. (2017), "Wage- vs. profit-led growth: the role of the distribution of wages in determining regime character," Cambridge Journal of Economics, 41(1), 49-61.

Risler, L. (2016), Three Essays on the Impact of Inflation Targeting in Developing and Emerging Countries, unpublished PhD dissertation, American University, Washington, DC.

Rochon, L.-P., and M. Setterfield (2012), "A Kaleckian model of growth and distribution with conflict-inflation and Post Keynesian nominal interest rate rules," Journal of Post Keynesian Economics, 34(3), 497-520.

Skott, P. (2017), “Weaknesses of 'wage-led growth,"” Review of Keynesian Economics, 5(3), 336-59.

Steindl, J. (1952), Maturity and Stagnation in American Capitalism, Oxford: Blackwell; reprinted New York: Monthly Review Press, 1976.

Stockhammer, E. (2013), "Why have wage shares fallen? an analysis of the determinants of functional income distribution," in M. Lavoie and E. Stockhammer (eds), Wage-led Growth: An Equitable Strategy for Economic Recovery, Basingstoke: Palgrave Macmillan, pp. 40-70.

Stockhammer, E. (2017), "Wage-led versus profit-led demand: what have we learned? A Kaleckian-Minskyan view," Review of Keynesian Economics, 5(1), 25-42.

Stockhammer, E., and J. Michell (2017), "Pseudo-Goodwin cycles in a Minsky model," Cambridge Journal of Economics, 41(1), 105-25 .

Stockhammer, E., and R. Wildauer (2016), "Debt-driven growth? wealth, distribution and demand in OECD countries," Cambridge Journal of Economics, 40(6), 1609-34.

Storm, S., and C.W.M. Naastepad (2012), Macroeconomics Beyond the NAIRU, Cambridge, MA: Harvard University Press.

Tori, D., and Ö. Onaran (2017), "The effects of financialisation and financial development on investment: Evidence from firm-level data in Europe," working paper, Greenwich Political Economy Research Center (GPERC). 
Wolff, E. (2015), "Inequality and rising profitability in the United States, 1947-2012," International Review of Applied Economics, 29(6), 741-69. 


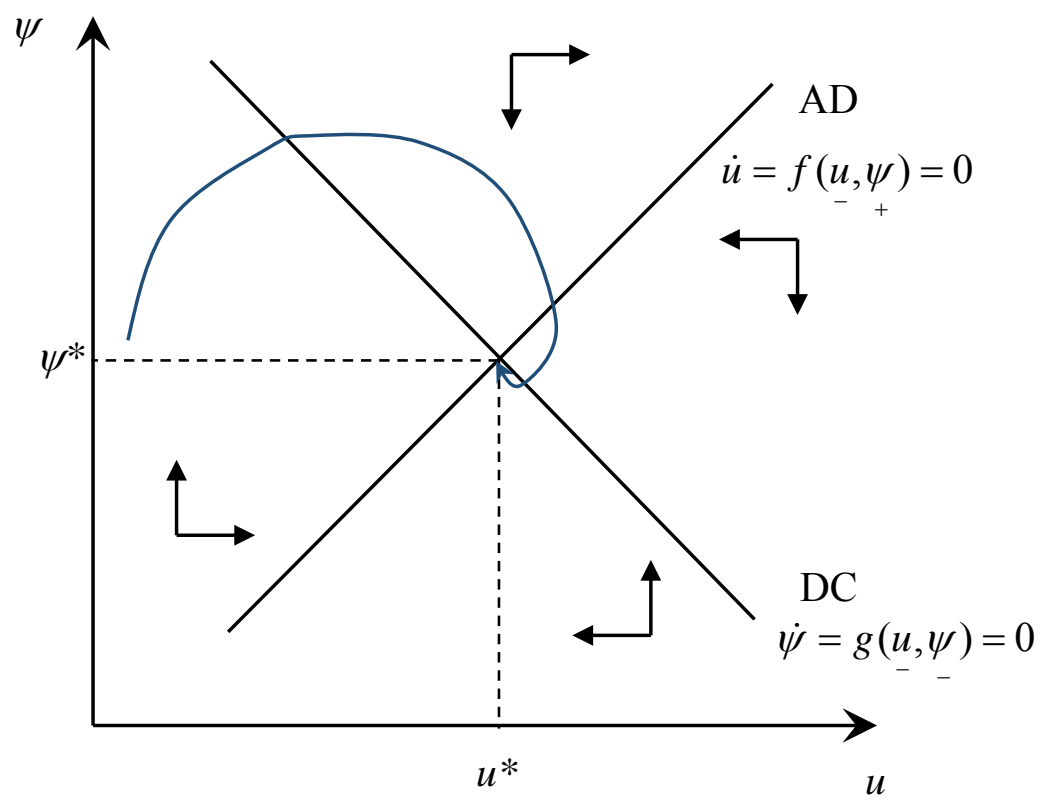

Panel (a) Wage-led demand, wage squeeze

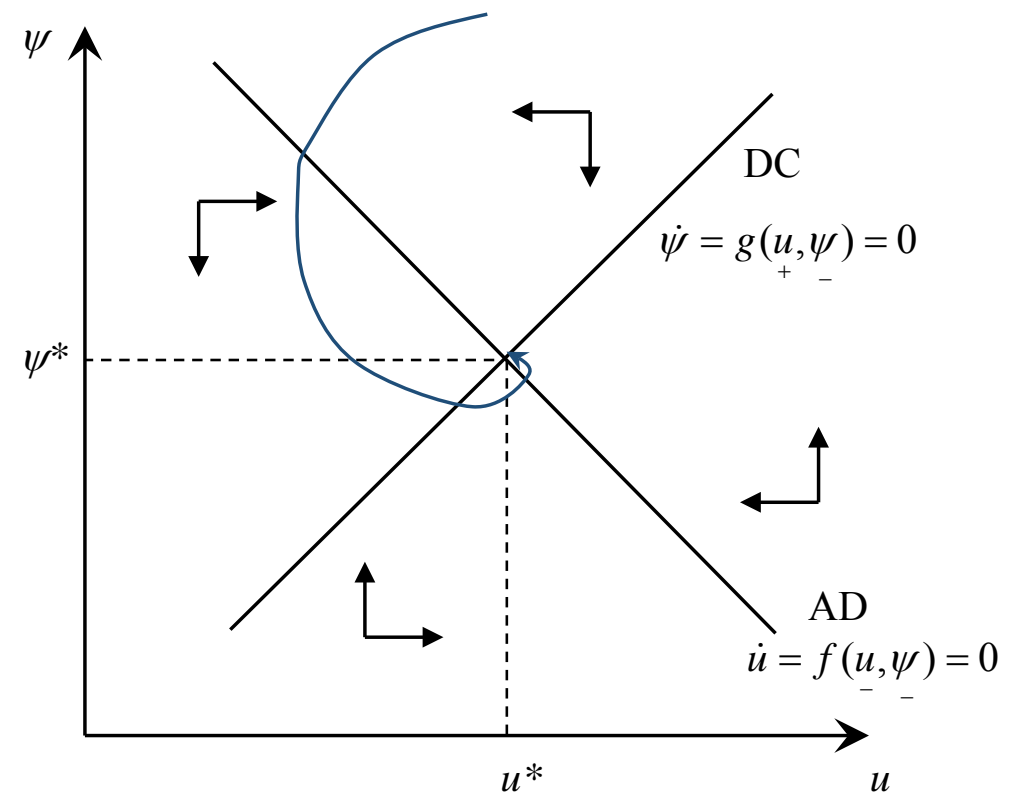

Panel (b) Profit-led demand, profit squeeze (neo-Goodwinian cycles)

Figure 1 Alternative visions of short-run cyclical dynamics 


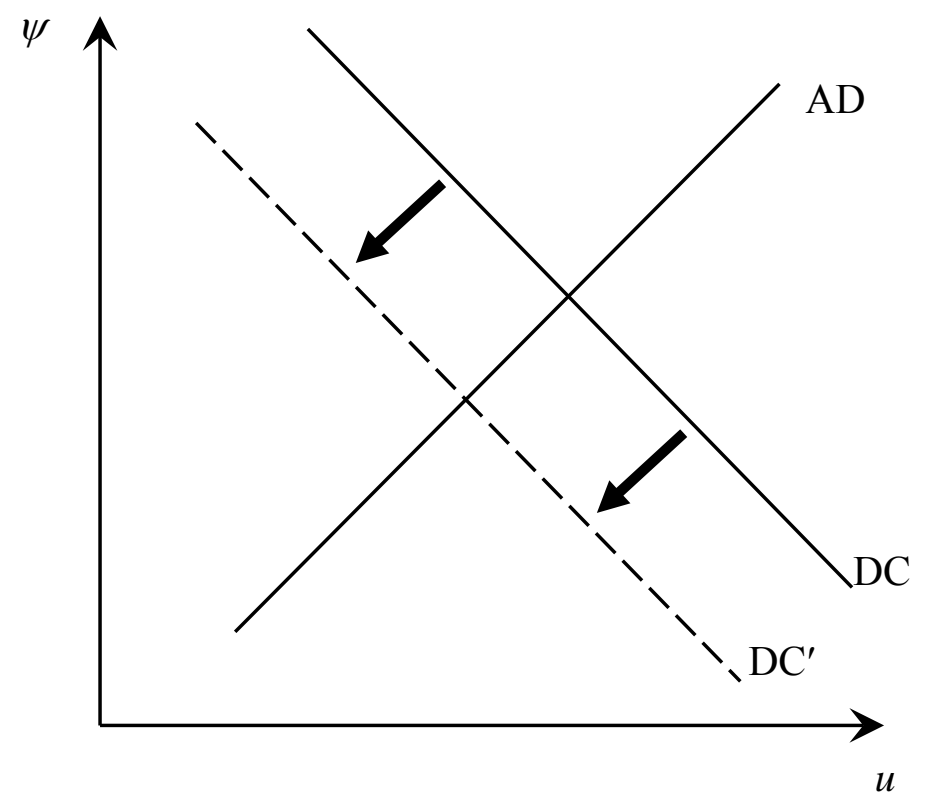

Panel (a) Wage-led demand, wage squeeze case

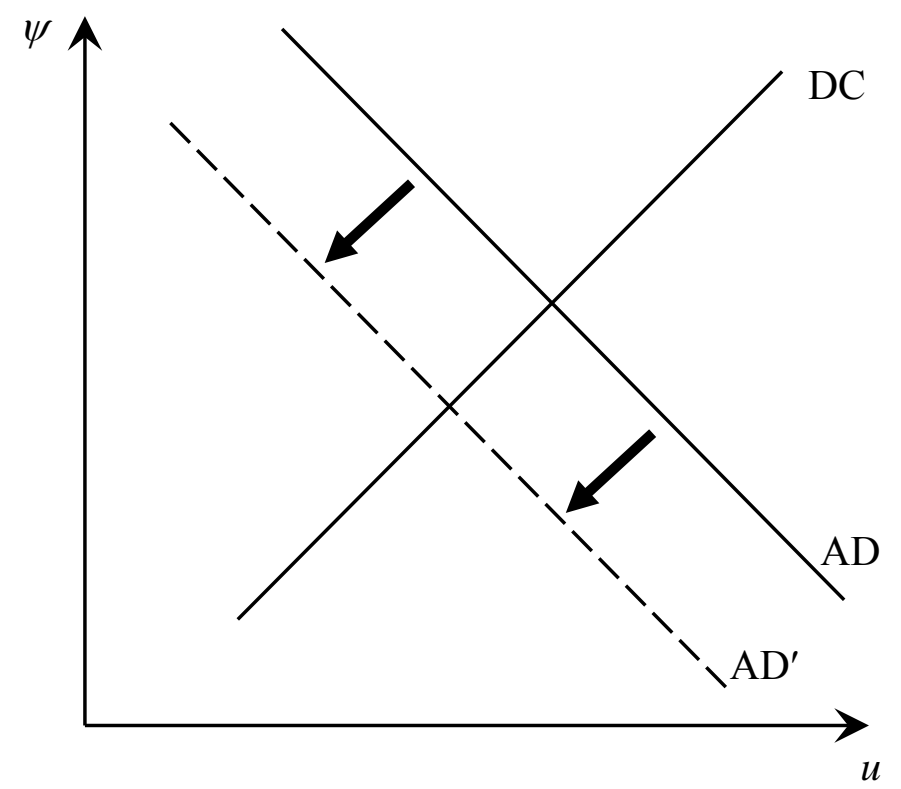

Panel (b) Profit-led demand, profit squeeze case

Figure 2 Alternative long-term shifts yielding a lower equilibrium wage share and a lower equilibrium utilization (or growth) rate 


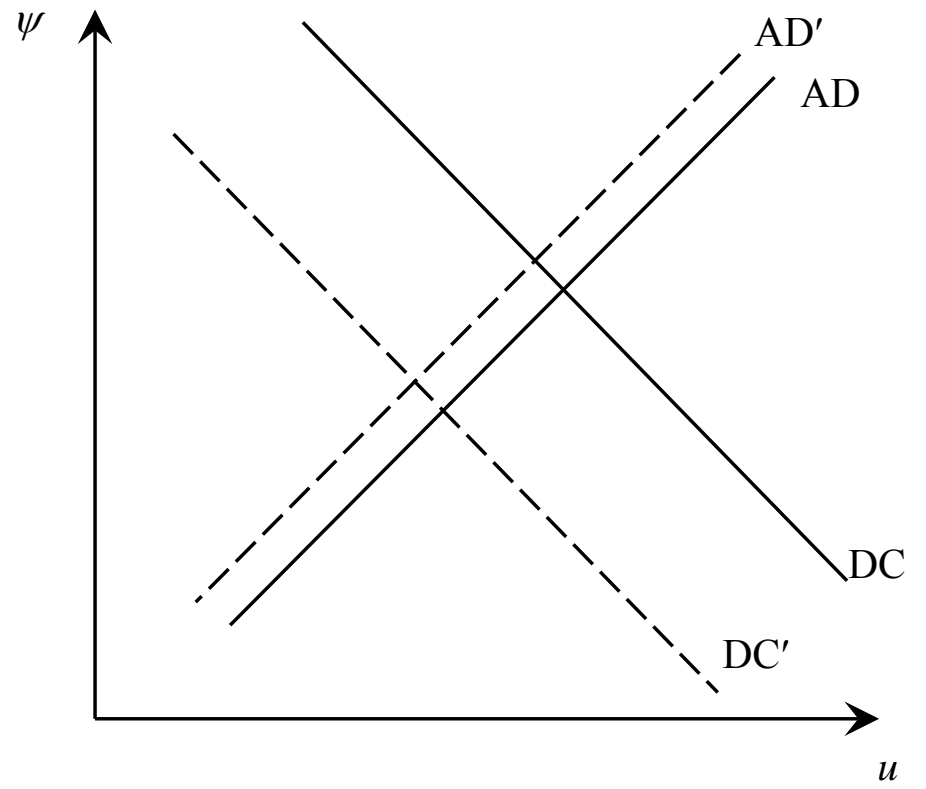

Panel (a) Wage-led demand, wage squeeze case

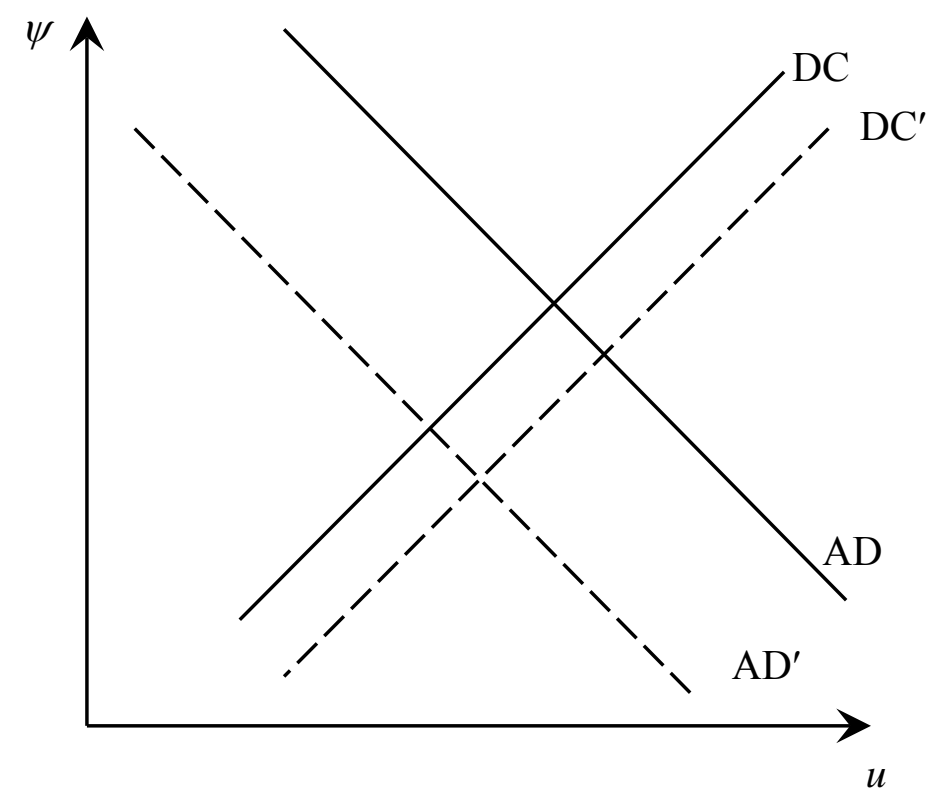

Panel (b) Profit-led demand, profit squeeze case

Figure 3 Combinations of shifts in $\mathrm{AD}$ and $\mathrm{DC}$ yielding a lower equilibrium wage share and a lower equilibrium utilization rate 


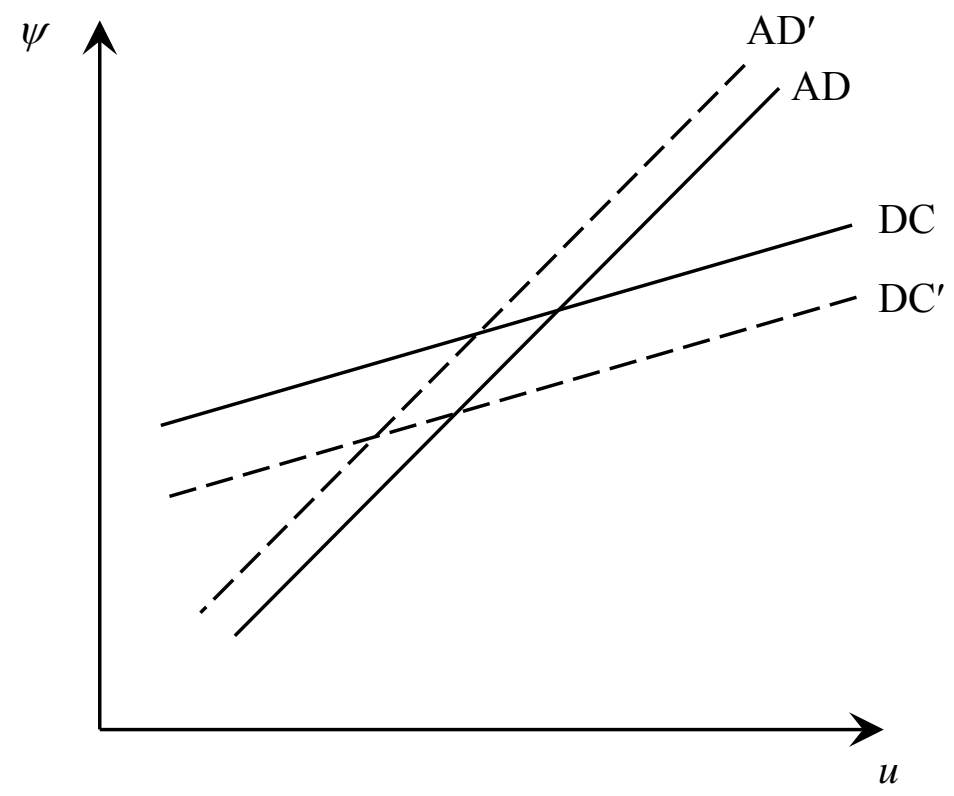

Panel (c) Wage-led demand, profit-squeeze case

Figure 3 continued. 